\title{
EFFECT OF ACTIVE LEARNING ON PERCEPTION OF AND PERFORMANCE IN SCIENCE SUBJECTS
}

\author{
Milan Kubiatko \\ University of Zilina, Slovakia
}

\begin{abstract}
Dear readers, I would like to thank the editor of the journal for the space to write some words about including a new technique (active learning) into the learning process. I try to introduce the topic of active learning and sketch some points, which is not applicable in the schools. This problem is typical for the countries of middle Europe, but it is possible to find it in other countries as well.

Active learning is a form of learning in which teaching strives to involve students in the learning process more directly than in other methods. This term has got many synonyms like learning through play, technology based learning, activity based learning, group work, project method, etc. the underlying factor behind these are some significant qualities and characteristics of active learning. The term "active learning" was introduced by the English scholar R. W. Revans. The definition was developing through time. In more detail, in active learning, students must do more than just listen: They must read, write, discuss, or be engaged in solving problems. It relates to the three learning domains referred to as knowledge, skills and attitudes (KSA). In particular, students must engage in such higher-order thinking tasks as analysis, synthesis, and evaluation. Active learning engages students in two aspects - doing things and thinking about the things they are doing (Renkl et al., 2002). Active learning should transform students from passive listeners to active participants, helps the student understand the subject through inquiry, gathering and analyzing data to solving higher order cognitive problems. There is intensive use of scientific and quantitative literacy across the curriculum, and technology based learning is also in high demand in concern with active learning.

It is possible to show some active learning exercises suggested learners work collaboratively, discuss materials while role-playing, debate, engage in case study, take part in cooperative learning, or produce short written exercises, etc. The argument is "when active learning exercises should be used during instruction?". Numerous studies have shown that introducing active learning activities (such as simulations, games, contrasting cases, labs...) before, rather than after lectures or readings, results in deeper learning, understanding, and transfer. The degree of instructor guidance students need while being "active" may vary according to the task and its place in a teaching unit. In an active learning environment learners are immersed in experiences within which they engage in meaningmaking inquiry, action, imagination, invention, interaction, hypothesizing and personal reflection (Cranton 2012).

It seems, that active learning has got "open door" to be successfully implemented in the learning process in all subjects. However, the situation is not so optimal as we can imagine. In many universities, lecture still looks like to be a centerpiece of instruction, where students passively listen and absorb kinds of information and then regurgitate it in response to periodic multiple-choice exams. And, maybe it is the place, where the mistake is occurring. If future teachers are preparing for their future work using this style of teaching, there is a big chance that they will teach in a similar way. This fact is mentioned in the study of Marton \& Saljo (1976), teaching assistants
\end{abstract}


ISSN 1648-3898/Print/

ISSN 2538-7138/Online/

are in many cases forced to use only passive form of presentation in seminars. Discussion sections or any other communication methods are missing in the seminars and they are used very rarely. This situation does not mean good expectations to the applications of new and non-traditional methods of teaching in the elementary and high schools. If future teachers do not try in the lectures and seminars of science subjects didactics new form of learning (in our case active learning), it is hard to wait, that they will applicate in their lessons of science subjects. And active learning techniques yield many benefits - they are student-centered; they maximize participation; they are highly motivational; and they give life and immediacy to the subject matter by encouraging students to move beyond a superficial, fact-based approach to the material. There are also examples from practice about the utility of active learning. McCarthy \& Anderson (2000) mentioned an experiment about direct controlled comparison between the standard lecture format and the cooperative learning format in an introductory college-level biology course. They reported that students taking the cooperative format option indicated significantly higher levels of satisfaction with the course than those taking the traditional format option. Similarly, Ambruster et al. (2009) compared responses of students on traditional lectures and non-traditional lectures. Students answered, that traditional course evaluations indicated that students were not satisfied with the course and did not recognize the importance of the course content to their education as biologists. For example, students often commented on course evaluations that the lectures and/or course materials were "boring."

So, it is obvious and it is possible to find more articles, where there are advantages of active learning and its form is mentioned and described. So the question is, why it is not implemented in the schools? Below, it is described, that there is a problem in universities, which are preparing future teachers of science subjects. And it is truth, because if teachers have not got examples of non-traditional techniques, the implementation of them is not possible. Maybe, it is caused by curriculum and duties of college employees, that they should teach according any plans, where non-traditional methods are not mentioned. Generally, it is relatively a big problem to incorporate new techniques in the learning process, this process is very slow, but all people, not only teachers, who are fans of new techniques, which can improve the interest of pupils and students about science subjects know, that one time the situation will be better.

\section{References}

Ambruster, P., Patel, M., Johnson, E., \&Weiss, M. (2009). Active learning and student-centered pedagogy improve student attitudes and performance in introductory biology. CBE - Life Sciences Education, 8 (3), 203-213.

Cranton, P. (2012). Planning instruction for adult learners (3rd Ed.). Toronto: Wall \& Emerson.

Marton, F., \& Saljo, R. (1976). On qualitative differences in learning: I $\square$ outcomes and process. British Journal of Educational Psychology, 46 (1), 4-11.

McCarthy, J. P., \& Anderson, L. (2000). Active learning techniques versus traditional teaching styles: Two experiments from history and political science. Innovative Higher Education, 24 (4), 279-294.

Renkl, A., Atkinson, R. K., Maier, U. H., \& Staley, R. (2002). From example study to problem solving: Smooth transitions help learning. Journal of Experimental Education, 70 (4), 293-315. 